\title{
ON THE MEAN MODULUS OF TRIGONOMETRIC POLYNOMIALS AND A CONJECTURE OF S. CHOWLA
}

\author{
J. CHIDAMBARASWAMY
}

ABSTRACT. Let $\left\{m_{k}\right\}$ be a strictly increasing sequence of positive integers. S. Chowla (1965) conjectured that

$$
\min _{0 \leqq x<1} \sum_{k=1}^{n} \cos 2 \pi m_{k} x<-c n^{1 / 2}
$$

$c>0$ being an absolute constant. Let $K_{1}, K_{2}, \cdots, K_{N}$ be the distinct integers $m_{l}-m_{k}, 1 \leqq k<l \leqq n ; r_{j}, 1 \leqq j \leqq N$, the number of pairs $(k, l)$ with $1 \leqq k<l \leqq n$ and $m_{l}-m_{k}=K_{j} ;$ and

$$
r(n)=\max _{1 \leqq j \leqq N} r_{j} .
$$

Lower bounds for $\int_{0}^{1}\left|\sum_{k=1}^{n} c_{k} e^{2 \pi i m_{k} \cdot x^{x}}\right| d x, c_{k}$ arbitrary complex numbers and $\int_{0}^{1}\left|\sum_{k=1}^{n} \gamma_{k} \cos 2 \pi\left(m_{k} x+\alpha_{k}\right)\right| d x, \gamma_{k} \geqq 0, \alpha_{k}$ real, are obtained in terms of $n, r(n)$ and the $c_{k}$ and $\gamma_{k}$ respectively and it has been deduced that in case $r(n)=\delta$, independent of $n$, then

$$
\min _{0 \leqq x<1} \sum_{k=1}^{n} \cos 2 \pi m_{k} x<-\frac{1}{2^{5 / 2}} \frac{1}{(\delta+1)^{1 / 2}} n^{1 / 2} .
$$

1. Introduction. Throughout the following $\left\{m_{k}\right\}$ stands for a strictly increasing sequence of positive integers. Chowla [2] conjectured that for any sequence $\left\{m_{k}\right\}$

$$
\min _{0 \leqq x<1} \sum_{k=1}^{n} \cos 2 \pi m_{k} x<-c n^{1 / 2},
$$

$c>0$ being an absolute constant. Uchiyama [4] proved that given any $n$ distinct positive integers $m_{1}, m_{2}, \cdots, m_{n}$ there exists a subset $m_{j_{1}}, m_{j_{2}}, \cdots$, $m_{j_{r}}$ of $m_{1}, m_{2}, \cdots, m_{n}$ such that

$$
\min _{0 \leqq x<1} \sum_{k=1}^{r} \cos 2 \pi m_{j_{k}} x<-\left(\frac{1}{4}\right)\left(\frac{1}{6}\right)^{1 / 2} n^{1 / 2} .
$$

Received by the editors December 10, 1971 and, in revised form, February 29, 1972. AMS 1970 subject classifications. Primary 42A04, 26A82.

Key words and phrases. Trigonometric polynomial, mean modulus, Hölder inequality.

(c) American Mathematical Society 1972 
In [3] Kurtz and Shah proved that

$$
\min _{0 \leq x<1} \sum_{k=1}^{n} \cos 2 \pi m_{k} x<-\left(\frac{1}{8}\right) n^{1 / 2}
$$

for a special class of sequences which they call admissible sequences. A sequence $\left\{m_{k}\right\}$ is called admissible if $m_{k}-m_{j}+m_{l}-m_{p} \neq 0$ if $k \neq j, k \neq p$, and $j \neq l$ all hold (see [3]).

The purpose of this paper is to prove (1.1) for much more general classes of sequences $\left\{m_{k}\right\}$. Specifically, let $N=N(n)$ be the number of distinct positive integers $m_{l}-m_{k}, 1 \leqq k<l \leqq n$, and let these distinct integers be denoted by $K_{1}, K_{2}, \cdots, K_{N}$. Also, let for $1 \leqq j \leqq N, r_{j}$ be the number of pairs $(k, l)$ such that $1 \leqq k<l \leqq n$ and $m_{l}-m_{k}=K_{j}$, and $r(n)=\max \left\{r_{1}, r_{2}, \cdots, r_{N}\right\}$. We shall prove (see Corollary 2.4) that, if $r(n)$ is independent of $n$, say $r(n)=\delta$, then (1.1) is true with $c=$ $\left(\frac{1}{2}\right)^{5 / 2}\left(1 /(\delta+1)^{1 / 2}\right)$. We shall denote the class of all sequences $\left\{m_{k}\right\}$ with $r(n)=\delta$ by $B_{\delta}$.

Let, for arbitrary complex sequence $\left\{c_{k}\right\}$,

and finally,

$$
S_{n}(x)=\sum_{k=1}^{n} c_{k} e\left(m_{k} x\right), \quad e(x)=\exp (2 \pi i x)
$$

$$
R_{n}=\sum_{k=1}^{n}\left|c_{k}\right|^{2}, \quad T_{n}=\sum_{k=1}^{n}\left|c_{k}\right|^{4}
$$

$$
L_{j}=\sum_{m_{l}-m_{l}=K j: 1 \leq k<l \leqq n} \operatorname{Re}\left(c_{k} \bar{c}_{l}\right), \quad M_{j}=\sum_{m_{l}-m_{k}=K_{j}: 1 \leqq k<l \leqq n} \operatorname{Im}\left(c_{k} \bar{c}_{l}\right),
$$

$$
L=\sum_{j=1}^{N} L_{j}^{2}, \quad M=\sum_{j=1}^{N} M_{j}^{2}
$$

where $\gamma_{k} \geqq 0$, and $\alpha_{k}$ real.

Lower bounds for the mean modulus $\int_{0}^{1}\left|S_{n}(x)\right| d x$ and $\int_{0}^{1}\left|T_{n}(x)\right| d x$ are obtained (Theorems 1 and 2 ) for arbitrary sequences $\left\{m_{k}\right\}$. We note that our results contain the results of [3] for admissible sequences (see the remark following Corollary 2.4). For results of different type on the $\min T_{n}(x)$, we refer to Theorem 3 of [1] and Theorem 4 of [3].

2. THEOREM 1. For any sequence $\left\{m_{k}\right\}$

$$
\int_{0}^{1}\left|S_{n}(x)\right| d x \geqq \frac{R_{n}^{1 / 2}}{\left(1+r(n)-\frac{1}{n}\right)^{1 / 2}}, \quad n=1,2,3, \cdots
$$


Corollary 1.1. For any sequence $\left\{m_{k}\right\} \in B_{\delta}$

$$
\int_{0}^{1}\left|S_{n}(x)\right| d x \geqq \frac{R_{n}^{1 / 2}}{\left(1+\delta-\frac{1}{n}\right)^{1 / 2}}, \quad n=1,2,3, \cdots .
$$

For the real series, we have

THEOREM 2. For any sequence $\left\{m_{k}\right\}$,

$$
\int_{0}^{1}\left|T_{n}(x)\right| d x \geqq \frac{1}{2^{3 / 2}} \frac{\left\{\sum_{k=1}^{n} \gamma_{k}^{2}\right\}^{1 / 2}}{\left(1+r(n)-\frac{1}{n}\right)^{1 / 2}}, \quad n=1,2,3, \cdots .
$$

COROLlaRY 2.1. For any sequence $\left\{m_{k}\right\} \in B_{\delta}$

$$
\int_{0}^{1}\left|T_{n}(x)\right| d x \geqq \frac{1}{2^{3 / 2}} \frac{\left\{\sum_{k=1}^{n} \gamma_{k}^{2}\right\}^{1 / 2}}{\left(1+\delta-\frac{1}{n}\right)^{1 / 2}}, \quad n=1,2,3, \cdots .
$$

COROLlaRY 2.2. For any sequence $\left\{m_{k}\right\}$,

$$
\min _{0 \leqq x<1} T_{n}(x) \leqq-\frac{1}{2^{5 / 2}} \frac{\left\{\sum_{k=1}^{n} \gamma_{k}^{2}\right\}^{1 / 2}}{\left(1+r(n)-\frac{1}{n}\right)^{1 / 2}}, \quad n=1,2,3, \cdots
$$

COROLlaRY 2.3. For any sequence $\left\{m_{k}\right\} \in B_{\delta}$

$$
\min _{0 \leqq x<1} T_{n}(x) \leqq-\frac{1}{2^{5 / 2}} \frac{\left\{\sum_{k=1}^{n} \gamma_{k}^{2}\right\}^{1 / 2}}{\left(1+\delta-\frac{1}{n}\right)^{1 / 2}}, \quad n=1,2,3, \cdots
$$

COROLlaRY 2.4. For any sequence $\left\{m_{k}\right\} \in B_{\delta}$

$$
\min _{0 \leqq x<1} \sum_{k=1}^{n} \cos 2 \pi m_{k} x<-\frac{n^{1 / 2}}{2^{5 / 2}(1+\delta)^{1 / 2}}, \quad n=1,2,3, \cdots .
$$

REMARK. It is not hard to see that if $\left\{m_{k}\right\}$ is admissible, $\delta=1$ and our Corollaries $1.1,2.1,2.3$, and 2.4 reduce to Theorems $1,2,3$ and Corollary of [3]. 
3. We need only to prove Theorems 1 and 2 and the Corollary 2.2 . The proofs of Theorem 2 and Corollary 2.2 are similar to the proofs of Theorems 2 and 3 respectively of [3]. We skip some of the details in the proof of Theorem 2 and the proof of Corollary 2.2, referring the reader to [3].

LEMMA 1. $\int_{0}^{1}\left|S_{n}(x)\right|^{4} d x=R_{n}^{2}+2(L+M)$.

Proof. We have

$$
\begin{aligned}
\left|S_{n}(x)\right|^{2} & =\left\{\sum_{k=1}^{n} c_{k} e\left(m_{k} x\right)\right\}\left\{\sum_{k=1}^{n} \bar{c}_{k} e\left(-m_{k} x\right)\right\} \\
& =\sum_{k=1}^{n}\left|c_{k}\right|^{2}+\sum_{k \neq l: 1 \leqq k, l \leqq n} c_{k} \bar{c}_{l} e\left(\left(m_{k}-m_{l}\right) x\right) \\
& =R_{n}+\sum_{1 \leqq k<l \leqq n}\left\{c_{k} \bar{c}_{l} e\left(\left(m_{k}-m_{l}\right) x\right)+c_{l} \bar{c}_{k} e\left(\left(m_{l}-m_{k}\right) x\right)\right\} \\
& =R_{n}+2 \sum_{1 \leqq k<l \leqq n}\left\{\operatorname{Re}\left(c_{k} \bar{c}_{l}\right) \cos 2 \pi\left(m_{l}-m_{k}\right) x\right. \\
& \left.\quad+\operatorname{Im}\left(c_{k} \bar{c}_{l}\right) \sin 2 \pi\left(m_{l}-m_{k}\right) x\right\}
\end{aligned}
$$

which, by $(1.6)$, is

$$
=R_{n}+2 \sum_{j=1}^{N}\left\{L_{j} \cos 2 \pi K_{j} x+M_{j} \sin 2 \pi K_{j} x\right\} .
$$

Now, since the $K_{j}, 1 \leqq j \leqq N$, are all distinct positive integers, it follows from (3.1) that

$$
\int_{0}^{1}\left|S_{n}(x)\right|^{4} d x=R_{n}^{2}+2 \sum_{j=1}^{N}\left(L_{j}^{2}+M_{j}^{2}\right)
$$

and the lemma follows in virtue of (1.7).

Proof of Theorem 1. By (1.6) and (1.7) we have

$$
\begin{aligned}
L+M= & \sum_{j=1}^{N}\left\{\sum_{m_{l}-m_{k}=K_{j ; 1} \leqq k<l \leqq n} \operatorname{Re}\left(c_{k} \bar{c}_{l}\right)\right\}^{2} \\
& +\sum_{j=1}^{N}\left\{\sum_{m_{l}-m_{k}=K_{j ; 1} \leqq k<l \leqq n} \operatorname{Im}\left(c_{k} \bar{c}_{l}\right)\right\}^{2} \\
\leqq & \sum_{j=1}^{N}\left\{\sum_{m_{l}-m_{k}=K_{j ; 1} \leqq k<l \leqq n}\left|\operatorname{Re}\left(c_{k} \bar{c}_{l}\right)\right|\right\}^{2} \\
& +\sum_{j=1}^{N}\left\{\sum_{m_{l}-m_{k}=K_{j ; 1} \leqq k<l \leqq n} \mid \operatorname{Im}\left(c_{k} \bar{c}_{l}\right)\right\}^{2}
\end{aligned}
$$


and this by the Hölder inequality is

$$
\begin{aligned}
\leqq & \sum_{j=1}^{N} r_{j} \sum_{m_{l}-m_{k}=K ;: 1 \leqq k<l \leqq n}\left|\operatorname{Re}\left(c_{k} \bar{c}_{l}\right)\right|^{2} \\
& +\sum_{j=1}^{N} r_{j} \sum_{m_{l}-m_{k}=K ;: 1 \leqq k<l \leqq n}\left|\operatorname{Im}\left(c_{k} \bar{c}_{l}\right)\right|^{2} \\
\leqq & r(n) \sum_{j=1}^{N} \sum_{m_{l}-m_{k}=K ;: 1 \leqq k<l \leqq n}\left\{\left|\operatorname{Re}\left(c_{k} \bar{c}_{l}\right)\right|^{2}+\left|\operatorname{Im}\left(c_{k} \bar{c}_{l}\right)\right|^{2}\right\} \\
= & r(n) \sum_{1 \leqq k<l \leqq n}\left|c_{k}\right|^{2}\left|c_{l}\right|^{2} . \\
R_{n}^{2}- & T_{n}=\left\{\sum_{k=1}^{n}\left|c_{k}\right|^{2}\right\}^{2}-\sum_{k=l}^{n}\left|c_{k}\right|^{4}=2 \sum_{1 \leqq k<l \leqq n}\left|c_{k}\right|^{2}\left|c_{l}\right|^{2},
\end{aligned}
$$

and hence, we have, by Lemma $1,(3.2)$, and the fact that $r(n) \geqq 1$,

$$
\begin{aligned}
\int_{0}^{1}\left|S_{n}(x)\right|^{4} d x & \leqq R_{n}^{2}+r(n)\left\{R_{n}^{2}-T_{n}\right\} \\
& \leqq R_{n}^{2}\{1+r(n)\}-T_{n} .
\end{aligned}
$$

Now, by the Hölder inequality,

and this, using the fact that

$$
\left\{\int_{0}^{1}\left|S_{n}(x)\right| d x\right\}^{2 / 3} \geqq \frac{\int_{0}^{1}\left|S_{n}(x)\right|^{2} d x}{\left\{\int_{0}^{1}\left|S_{n}(x)\right|^{4} d x\right\}^{1 / 3}}
$$

$$
\begin{aligned}
\int_{0}^{1}\left|S_{n}(x)\right|^{2} d x & =R_{n} \quad(\operatorname{see}(3.1)), \text { and }(3.3), \\
& \geqq \frac{R_{n}}{\left\{R_{n}^{2}(1+r(n))-T_{n}\right\}^{1 / 3}} .
\end{aligned}
$$

Theorem 1 is clear since by the Schwarz inequality $R_{n}^{2} \leqq n T_{n}$.

ProOF OF TheOREM 2 . If

$$
U_{n}(x)=\sum_{k=1}^{n} \gamma_{k} e\left(m_{k} x+\alpha_{k}\right)=\sum_{k=1}^{n} \gamma_{k} e\left(\alpha_{k}\right) e\left(m_{k} x\right),
$$

$T_{n}(x)=\operatorname{Re}\left(U_{n}(x)\right)$, and hence, using (3.3),

$$
\begin{aligned}
\int_{0}^{1}\left|T_{n}(x)\right|^{4} d x \leqq & \int_{0}^{1}\left|U_{n}(x)\right|^{4} d x \leqq\left\{\sum_{k=1}^{n}\left|\gamma_{k} e\left(\alpha_{k}\right)\right|^{2}\right\}^{2}(1+r(n)) \\
& -\sum_{k=1}^{n}\left|\gamma_{k} e\left(\alpha_{k}\right)\right|^{4}=\left\{\sum_{k=1}^{n} \gamma_{k}^{2}\right\}^{2}(1+r(n))-\sum_{k=1}^{n} \gamma_{k}^{4}
\end{aligned}
$$


From now on, the proof runs as that of Theorem 2 of [3] and we omit the details.

\section{REFERENCES}

1. J. Chidambaraswamy and S. M. Shah, Trigonometric series with nonnegative partial sums, J. Reine Angew. Math. 229 (1968), 163-169. MR 36 \#6861.

2. S. Chowla, Some applications of a method of A. Selberg, J. Reine Angew. Math. 217 (1965), 128-132. MR 30 \#3070.

3. L. C. Kurtz and S. M. Shah, On the $L^{1}$ norm and the mean value of a trigonometric series, Proc. Amer. Math. Soc. 19 (1968), 1023-1028. MR 37 \#6663.

4. S. Uchiyama, On the mean modulus of trigonometric polynomials whose coefficients have random signs, Proc. Amer. Math. Soc. 16 (1965), 1185-1190. MR 32 \#2830.

Department of Mathematics, University of Toledo, Toledo, Ohio 43606 